\title{
The Appearance of The Infraorbital Canal and Infraorbital Ethmoid (Haller's) Cells on Panoramic Radiography of Edentulous Patients
}

\author{
Esra Yesilova (iD) and Ibrahim Sevki Bayrakdar \\ Oral and Maxillofacial Radiology Department, Faculty of Dentistry, Eskişehir Osmangazi University, Eskişehir, Turkey \\ Correspondence should be addressed to Esra Yesilova; dtesra@hotmail.com
}

Received 19 February 2018; Revised 29 May 2018; Accepted 30 May 2018; Published 8 July 2018

Academic Editor: Giulio Gasparini

Copyright (c) 2018 Esra Yesilova and Ibrahim Sevki Bayrakdar. This is an open access article distributed under the Creative Commons Attribution License, which permits unrestricted use, distribution, and reproduction in any medium, provided the original work is properly cited.

\begin{abstract}
Objectives. The aim of the study is to detect the prevalence and the characteristics of infraorbital canal and Haller's cells on panoramic radiography of edentulous patients. Methods. The study group comprised 291 panoramic radiographs of edentulous patients. Radiographs were interpreted for the visibility and characteristics of infraorbital canal and Haller's cells. For classification of infraorbital canal, a method based on the image characteristics of the border of the canal (Types I, II, and III) was used. Haller's cells were grouped according to the number and the shape of loculations. Results. Infraorbital canal was observed in 246 (84.6\%) radiographs. The most prevalent of the observed canals were Type III for both sides (39.9 \% for right and $32.3 \%$ for left side). The visibility of Haller's cells was $23.7 \%$. The frequencies of Haller's cells' visibility were approximately equal for both genders. There is no significant difference between genders for the visibility of infraorbital canal and Haller's cells. Conclusions. The surgeons, implantologists, and radiologists should take into consideration infraorbital canal and Haller's cell for planning implant surgery of maxillary anterior region and undefined orofacial pain for edentulous patients.
\end{abstract}

\section{Introduction}

The infraorbital region is a passage between cranial fossa, osteomeatal complex, orbits, and the maxillary dental segment. The infraorbital nerve is one of the major anatomical structures of this region. It is a division of maxillary nerve, extending from the inferior orbital fissure to infraorbital foramen throughout maxillary sinus in the infraorbital canal/groove complex (ICG/C) [1-3].

There have been numerous radiological [1-5] and anatomical [6-10] studies about the infraorbital nerve's dimensions and types in both living persons and cadavers/skulls. Some authors reported anatomical variations $[11,12]$ and classifications [2-5] of ICG/C. With the introduction of threedimensional (3D) techniques to clinical practice, neighbouring anatomical variations were noticed, which affected the classifications [11]. Haller's cells are neighbouring structures of ICG/C. They are called either orbitoethmoidal cells or maxilloethmoidal cells. The name infraorbital ethmoid cell is more proposed to describe the site and the emergence of these objects. Haller's cells may be different in size, number, and shape [13]. When enlarged, they can significantly constrict posterior aspect of the infundibulum. These entities can be associated with symptoms of rhinosinusitis such as orofacial pain, headache, and impaired nasal breathing [14]. Isolated Haller's cell mucocele cases were reported $[15,16]$. Therefore the presence of Haller's cells is clinically significant. Even with rhinoscopy, it is not easy to observe Haller's cells because of their location, which may be near or extend into the infraorbital canal. Radiology is indispensable for diagnosis [15].

Panoramic radiography is a practical technique that presents an image of a large area including midface bones (nasal fossa, orbital fossae, and maxillary sinus) and teeth. Patients easily tolerate the application of this technique. Despite some structural superimpositions and magnifications [17], plain radiography is still the first choice for evaluation with a low radiation dose. It is commonly used to examine dentate and edentate jaws. In a review of related literature, Scarfe's [5] classification seems to be the only 


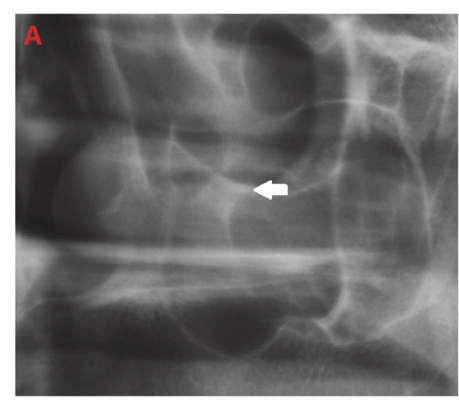

(a)

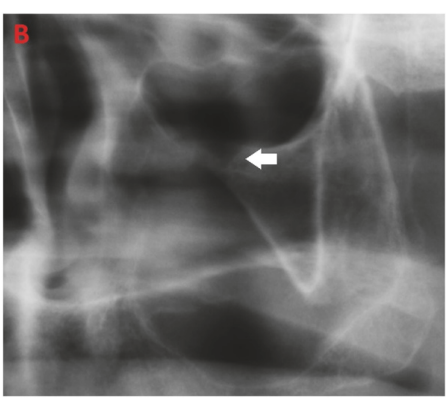

(b)

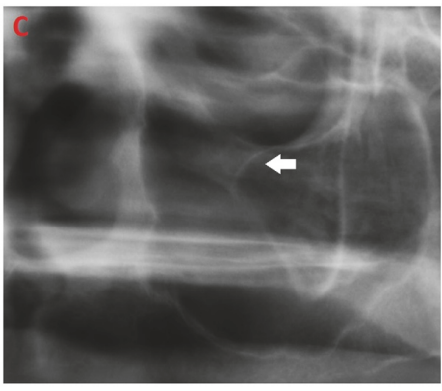

(c)

FIgURE 1: The cropped panoramic radiographic images show the types of infraorbital canals: (a) Type I, corticated both orbit and antrum parts corticated, (b) Type II, both orbit and antrum parts without cortication, and (c) Type III, orbital part without cortication, antrum part corticated.

one on evaluating the infraorbital canal with panoramic radiography. It is a simple and useful classification that will be described in more detail in the Methods and Materials of this paper. Haller's cell has also been demonstrated in panoramic images by some researchers $[13,14,18]$.

The rehabilitation of edentulous patients with implantsupported prosthesis now has an important role as a treatment modality in dental practice. While patients have expressed increased demand for implants, the amount and density of bone, metabolic bone disorders, and variations of adjacent anatomic structures are limiting factors. Sinuslifting techniques are needed to deal with atrophied alveolar ridges [19]. Surgical techniques require knowing region and its possible variations well. In upper jaw and midface surgeries, the knowledge of the infraorbital canal anatomical structure minimizes the damage to nerves in surgical approach of orbits, zygomatic process, and maxillary bone [3].

Other than prosthetic rehabilitation, edentulous patients also consult dentists for diagnosis and treatment of orofacial pain [20]. Sometimes patients have to visit different departments such as neurology, ear-nose-throat, and maxillofacial surgery to find the source of undefined pain. Diseases of anatomical variants may play a role in this kind of pain in edentulous patients [18].

The aim of this retrospective study is to detect the prevalence and the characteristics of infraorbital canal and Haller's cells through panoramic radiography of edentulous patients.

\section{Materials and Methods}

2.1. Study Design. The study group comprised 291 diagnostically acceptable panoramic radiographs of edentulous patients, randomly selected from the archive of Oral and Maxillofacial Radiology Department and evaluated retrospectively. The age range of patients was 38-88 years.

No ethical approval was required because no additional exposure of radiation was applied to the patients beyond routine diagnostic purpose in this retrospective study.

2.2. Data Collection. All radiographs were taken with a digital panoramic X-ray machine (Promax, Planmeca, Helsinki,
Finland) (64 kV, $6 \mathrm{~mA}, 16 \mathrm{~s})$. First, 60 radiographs were viewed on the same computer (MacBook Pro., China) and independently interpreted under optimal lighting conditions by two oral and maxillofacial radiologists. Interrater agreement was calculated. Kappa values were found with perfect agreement, 0.86 for Haller's cells and 0.89 for infraorbital canal, so all of the radiographs were interpreted with common agreement of two oral and maxillofacial radiologists for the visibility and characteristics of infraorbital canal and Haller's cells.

2.2.1. The Criteria for Classifying Infraorbital Canal. The radiographic characteristics of the border of the canals were grouped according to the classification of Scarfe [5] et al. (Figure 1).

Type I: Both the borders of the orbital and the antrum parts of the canal are radiopaque

Type II: Both the borders of the orbital and the antrum parts of the canal are invisible with no linear radiopacity

Type III: The orbital part of the canal is radiolucent with no linear radiopacity; the antrum part of the canal is radiopaque with linear radiopacity

2.3. Infraorbital Ethmoid Cell (Haller's Cell). Haller's cells were grouped according to the number and the shape of loculations as multilocular, unilocular with septae (clustered minor locules), or unilocular (without septae) (Figure 2).

The visibility of the canal and Haller's cells grouped as unilateral, bilateral, and no appearance. Identification of Haller's cell was made according to criteria of Ahmad et al. [13] as follows:

(1) Well-defined, round, tear-drop shaped radiolucency, single or multiple, unilocular or multilocular, with a smooth border, which may or may not be corticated

(2) Located medial to infraorbital foramen

(3) All or most of the border in the panoramic section being visible

(4) The inferior border of the orbit lacks cortication or remains indistinguishable in areas superimposed by this entity.

2.4. Statistical Analysis. Data were analyzed statistically with IBM SPSS Statistics 20.0 using frequencies/percentages, 


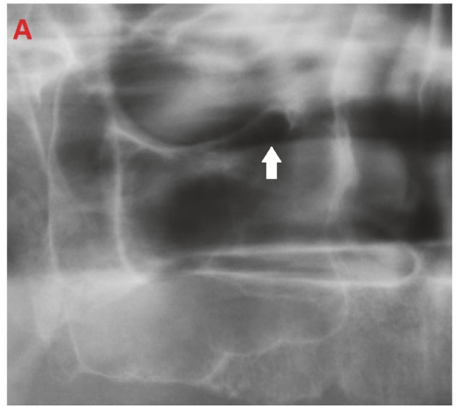

(a)

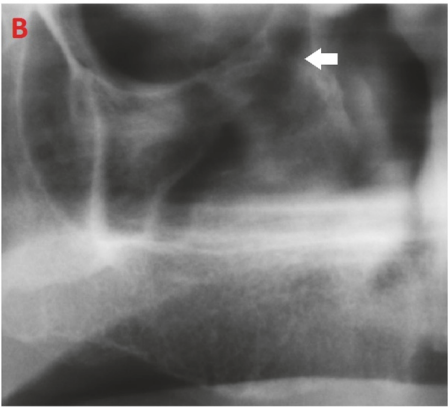

(b)

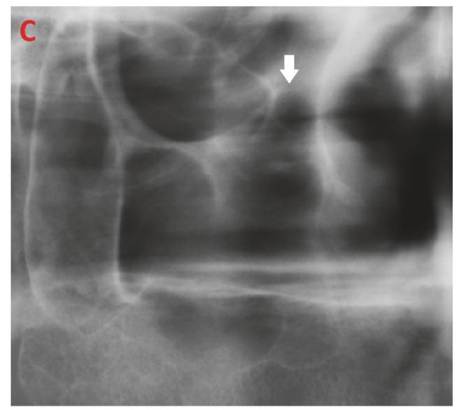

(c)

FIGURE 2: Types of infraorbital ethmoid cells (Haller's cells): (a) unilocular, (b) multilocular, and (c) unilocular with septae.

TABLE 1: Infraorbital canal (IOC) visibility sides and types.

\begin{tabular}{|c|c|c|c|c|}
\hline \multirow{12}{*}{ IOC } & \multirow{6}{*}{ Right side } & \multirow{3}{*}{ Unilateral } & Type 1 & $6(2.1 \%)$ \\
\hline & & & Type 2 & $4(1.4 \%)$ \\
\hline & & & Type 3 & $18(6.2 \%)$ \\
\hline & & \multirow{3}{*}{ Bilateral } & Type 1 & $79(27.1 \%)$ \\
\hline & & & Type 2 & $26(8.9 \%)$ \\
\hline & & & Type 3 & $98(33.7 \%)$ \\
\hline & \multirow{6}{*}{ Left side } & \multirow{3}{*}{ Unilateral } & Type 1 & $2(0.7 \%)$ \\
\hline & & & Type 2 & $6(2.1 \%)$ \\
\hline & & & Type 3 & $7(2.4 \%)$ \\
\hline & & \multirow{3}{*}{ Bilateral } & Type 1 & $79(27.1 \%)$ \\
\hline & & & Type 2 & $33(11.3 \%)$ \\
\hline & & & Type 3 & $87(29.9 \%)$ \\
\hline
\end{tabular}

descriptive statistics, cross table, and $\chi^{2}$ test to obtain the findings.

\section{Results}

The study group consisted of 291 radiographs from 103 males and 188 females, age ranging from 38 to 88 (mean $63.63 \pm 10.113)$.

3.1. Infraorbital Canal. Infraorbital canal was visible in 246 $(84.5 \%)$ of radiographs (Table 1). In 203 cases $(83 \%)$ it was observed bilaterally; in 43 cases (17\%) it was observed unilaterally. It was observed in $83.5 \%$ of male patients $(16 \%$ unilateral, $84 \%$ bilateral) and $85.1 \%$ of female patients $(18 \%$ unilateral, $82 \%$ bilateral). Most of the observed canals were Type III for both sides (50\% right and $44 \%$ left side). For the right side, 85 cases were Type I, 30 cases were Type II, and 116 cases were Type III. For the left side, 81 cases were Type I, 39 cases were Type II, and 94 cases were Type III. In 63 cases, a Type III canal was observed bilaterally.

There was no significant difference between genders for the visibility of infraorbital canal $(\mathrm{p}=0.877)$.

3.2. Haller's Cell. The prevalence of Haller's cells was $23.7 \%$, with 69 cases showing 88 Haller cells. Haller's cells were frequently $(72.5 \%)$ observed unilaterally. In 69 patients with Haller's cells, 50 were unilateral (equal for right and left sides) and 19 were bilateral. For the right side, 36 presentations were unilocular, 4 were multilocular, and 4 were unilocular with septae (clustered). For the left side, 37 presentations were unilocular, 1 was multilocular, and 6 were unilocular with septae (clustered) (Table 2). Most of the 19 bilaterally observed cells were unilocular, as in 14 cases.

Haller's cells were observed in $25.2 \%$ of cases with an observed infraorbital canal. In 16 cases, both Haller's cells and the infraorbital canal were observed bilaterally. Haller's cells were dominantly observed with Type III and I infraorbital canals. However there was no relationship between presence of Haller's cells and infraorbital canal types $(p=0.162)$.

Haller's cells were observed in $24.3 \%$ of male patients and $23.4 \%$ female patients. There was no significant difference between genders for the visibility of Haller's cells $(\mathrm{p}=0.871)$.

\section{Discussion}

This study evaluated the infraorbital canal and infraorbital ethmoid cells in panoramic radiography of edentulous patients concomitantly.

Studies of the infraorbital canal are in great demand within researchers working on this region because of its clinical importance. Morphometric analyses of the infraorbital canal are made on dry skulls [6-8, 10] and cadavers [9]. For surgical planning, the course of canal through the sinus and the relationship of canal with maxillary sinus septae 
TABLE 2: Infraorbital ethmoid cell (Haller's Cell) types and sides.

\begin{tabular}{|c|c|c|c|c|}
\hline \multirow{12}{*}{ Haller's Cell } & \multirow{6}{*}{ Right side } & \multirow{3}{*}{ Unilateral } & Unilocular & $20(6.9 \%)$ \\
\hline & & & Multilocular & $3(1 \%)$ \\
\hline & & & Unilocular with septae & $2(0.7 \%)$ \\
\hline & & \multirow{3}{*}{ Bilateral } & Unilocular & $16(5.5 \%)$ \\
\hline & & & Multilocular & $1(0.3 \%)$ \\
\hline & & & Unilocular with septae & $2(0.7 \%)$ \\
\hline & \multirow{6}{*}{ Left side } & \multirow{3}{*}{ Unilateral } & Unilocular & $21(7.2 \%)$ \\
\hline & & & Multilocular & $1(0.3 \%)$ \\
\hline & & & Unilocular with septae & $3(1.0 \%)$ \\
\hline & & \multirow{3}{*}{ Bilateral } & Unilocular & $16(5.5 \%)$ \\
\hline & & & Multilocular & $0(0 \%)$ \\
\hline & & & Unilocular with septae & $3(1.0 \%)$ \\
\hline
\end{tabular}

were studied with 3D imaging systems [3, 4]. Existing studies have all focused on possible anatomical variations to improve clinical applications [21].

Panoramic radiography creates two-dimensional (2D) images inferior to 3D systems. Nevertheless, there are some reasons for using panoramic radiography to distinguish the infraorbital canal. It enables the viewer to diagnose anatomical structures of a large area with single dose of low radiation. In addition, the projection angle of orthopantomography allows observation of the scope of infraorbital canal. As such, it is valuable to make this evaluation with this commonly used imaging technique [5].

Regardless of patient gender, canal was most commonly observed bilaterally. The first and second most observed types were Types III and I, respectively. The observation rate of the canals in panoramic radiography and the frequency of the types of the infraorbital canals are highly compatible with Scarfe's [5] results.

Haller's cells have been studied for different purposes, such as the prevalence and morphologic features of the cells and the role of the cells in rhinosinusitis. Some isolated Haller's cells pathologies $[15,16]$ occur in the literature. The reported incidence of Haller's cells varies according to imaging techniques, number of patients, and probably racial differences. This study was limited to a special population with an age group quite different from other studies. In other studies, a wide range was selected.

Our study found noticeable unilateral location and unilocular morphology of the cells and no relationship with gender. These findings are consistent with the findings of previous studies $[14,18]$. The prevalence of Haller's cell was founded between 16 and $38.2 \%$ in panoramic radiographic studies $[13,14,18]$. Our study's prevalence was within that range, at $23.7 \%$.

Panoramic radiography plays an important role in the determination of the infraorbital canal and Haller's cells in a considerable number of cases in dental practice. However, diagnostic value of panoramic radiography is limited because of inherited disadvantages. 3D images with thinner slices reveal cells more sensitively. But infraorbital canal and Haller's cells are anatomic variations [13]. Unless it is required to diagnose a suspicious pathology, there is no need for these sensitive images with their high radiation doses $[13,22]$.

When Haller's cells are inflamed, midface hypoesthesia may be experienced. In these cases, infraorbital nerve pathologies should be differentiated [15]. As mentioned above, the relationship between septae and the infraorbital canal has been studied with $3 \mathrm{D}$ techniques, notably in a study by Ference et al. [4] that included Haller's cells in the classification of these relationships. In our study, Haller's cells were observed in $25.2 \%$ of cases with an observed infraorbital canal, and Haller's cells were found most commonly with Type III and I infraorbital canals that had corticated borders in the maxillary sinus. It is possible to think that Ference's Type 3 canal, defined as the "descending" type that passes through the septa or is associated with Haller's cells, is compatible with our findings. The canal type associated with Haller's cells comes to an end in an infraorbital foramen that is $2.9 \mathrm{~mm}$ inferiorly localized compared to other types. This may be an effective guide for surgeons in clinical applications when $3 \mathrm{D}$ images are absent.

Classifications of the canal with computed tomography (CT) bring better visualization of the course of the canal and relationships $[3,4]$ than $2 \mathrm{D}$ images. In a recently published article [1], cone beam computed tomography (CBCT) was used for evaluation of the infraorbital canal through the maxillary sinus. Results of this CBCT study indicate that this technique may take place of CT, because of the low dose of radiation. We think that evaluation of panoramic radiography accurately will guide us for the next step toward use of 3D systems.

CBCT studies of Haller's cells have focused on the prevalence and role of these cells in rhinosinusitis [23-25]. Measurements of the infraorbital canal [26] and foramen $[26,27]$ show that CBCT has the potential to present this region in detail with low dose radiation. CBCT can also demonstrate relationships between different anatomical studies, as different classifications may be combined to establish a useful method for practice.

Magnetic resonance imaging (MRI) is not the first choice for drawing corticated anatomic structures [28] despite its advantage of lacking ionizing radiation. The excellent soft tissue resolution of MRI is utilized to visualize enlargement of 
the infraorbital nerve in orbital lymphoproliferative disorders [29] (pathognomonic for IgG4-related orbital disease), to depict tumors extended to sinonasal cavity from the intracranium, to show intracranial and orbital complications from sinusitis, inflammatory polyps, oedema [28], and trauma [30].

The infraorbital canal and Haller's cells were evaluated together in edentulous patients. Therefore mean age of the study group was higher $(63.63 \pm 10.113)$. This age range was selected to distinguish anatomic variations and undefined pain for the clinical evaluation of edentulous patients. Edentulous patients demand comfort for chewing and speaking. Furthermore, undefined pain felt in maxilla and mandible of edentulous patients may be diagnostically challenging for practitioners [20]. Longstanding edentulous alveolar ridges can atrophy and need surgical treatment for stabilization of prosthetic restoration. The recognition of radiographic imaging patterns of anatomical details is valuable for surgical planning [31].

\section{Conclusion}

To our knowledge, there has been no study in the literature assessing for both infraorbital ethmoid cells and the infraorbital canal on the edentulous patients' panoramic radiographs. that

The data obtained from our study encouraged us to think

(1) future studies may be focused on Haller's cells prevalence of patients who have unexplained pain;

(2) the course of infraorbital canal in the maxillary sinus and its relationship with sinus septae and Haller's cells must be studied in depth with CBCT, particularly by oral and maxillofacial radiologists and surgeons in dental practice.

\section{Data Availability}

The data used to support the findings of this study are available from the corresponding author upon request.

\section{Disclosure}

This study was presented as electronic poster in European Society of Head and Neck Radiology Congress, 22-24 Sept. 2016, Leiden, Holland.

\section{Conflicts of Interest}

The authors have no conflicts of interest regarding the present study.

\section{References}

[1] A. Haghnegahdar, L. Khojastepour, and A. Naderi, "Evaluation of Infraorbital Canal in Cone Beam Computed Tomography of Maxillary Sinus," Journal of Dentistry, vol. 19, no. 1, pp. 41-47, 2018.
[2] J. E. Lantos, A. N. Pearlman, A. Gupta et al., "Protrusion of the infraorbital nerve into the maxillary sinus on CT: Prevalence, proposed grading method, and suggested clinical implications," American Journal of Neuroradiology, vol. 37, no. 2, pp. 349-353, 2016.

[3] A. Yenigun, C. Gun, I. I. Uysal, and A. Nayman, "Radiological classification of the infraorbital canal and correlation with variants of neighboring structures," European Archives of OtoRhino-Laryngology, vol. 273, no. 1, pp. 139-144, 2016.

[4] E. H. Ference, S. S. Smith, D. Conley, and R. K. Chandra, "Surgical anatomy and variations of the infraorbital nerve," The Laryngoscope, vol. 125, no. 6, pp. 1296-1300, 2015.

[5] W. C. Scarfe, R. P. Langlais, T. Ohba, A. Kawamata, and I. Maselle, "Panoramic radiographic patterns of the infraorbital canal and anterior superior dental plexus," Dentomaxillofacial Radiology, vol. 27, no. 2, pp. 85-92, 1998.

[6] U.-Y. Lee, S.-H. Nam, S.-H. Han, K.-N. Choi, and T.-J. Kim, "Morphological characteristics of the infraorbital foramen and infraorbital canal using three-dimensional models," Surgical and Radiologic Anatomy, vol. 28, no. 2, pp. 115-120, 2006.

[7] Y. S. Nam, S. Bahk, and S. R. Eo, "Anatomical Study of the Infraorbital Nerve and Surrounding Structures for the Surgery of Orbital Floor Fractures," The Journal of Craniofacial Surgery, vol. 28, no. 4, pp. 1099-1104, 2017.

[8] Deepthi Nanayakkara, Roshan Peiris, Navini Mannapperuma, and Amal Vadysinghe, "Morphometric Analysis of the Infraorbital Foramen: The Clinical Relevance," Anatomy Research International, vol. 2016, pp. 1-8, 2016.

[9] D. C. Nguyen, S. J. Farber, G. T. Um, G. B. Skolnick, A. S. Woo, and K. B. Patel, "Anatomical study of the intraosseous pathway of the infraorbital nerve," The Journal of Craniofacial Surgery, vol. 27, no. 4, pp. 1094-1097, 2016.

[10] A. Przygocka, J. Szymański, E. Jakubczyk, K. Jȩdrzejewski, M. Topol, and M. Polguj, "Variations in the topography of the infraorbital canal/groove complex: A proposal for classification and its potential usefulness in orbital floor surgery," Folia Morphologica (Poland), vol. 72, no. 4, pp. 311-317, 2013.

[11] R. K. Chandra and D. W. Kennedy, "Surgical implications of an unusual anomaly of the infraorbital nerve," Ear, Nose \& Throat Journal, vol. 83, no. 11, pp. 766-767, 2004.

[12] S. Jakhere, V. Kalmath, and U. Chillalshetti, "Ectopic Infra Orbital Nerves: Case Series of a Dangerous Normal Variant," Acta Medica Indonesiana, vol. 50, no. 1, pp. 66-69, 2018.

[13] M. Ahmad, N. Khurana, J. Jaberi, C. Sampair, and R. K. Kuba, "Prevalence of infraorbital ethmoid (Haller's) cells on panoramic radiographs," Oral Surgery, Oral Medicine, Oral Pathology, Oral Radiology, and Endodontology, vol. 101, no. 5, pp. 658-661, 2006.

[14] J. Solanki, S. Gupta, N. Patil, M. Kulkarni Singh, and S. Laller, "Prevelance of Haller's Cells: A Panoramic Radiographic Study," Journal of Clinical and Diagnostic Research, vol. 8, no. 9, pp. C01C4, 2014.

[15] J. H. Choi, "Hypoesthesia of midface by isolated Haller's cell mucocele," Brazilian Journal of Otorhinolaryngology, 2016.

[16] S. Mohindra and S. Dhingra, "Isolated mucocele in an infraorbital ethmoidal-Haller cell: A unique presentation," Clinical Rhinology, vol. 6, no. 3, pp. 129-130, 2013.

[17] A. G. Lurie, "Panoramic Imaging," in Oral Radiology, S. C. White and M. J. Pharoah, Eds., pp. 175-190, Principles and interpretation, Elsevier, China, 6th edition, 2009. 
[18] A. Raina, M. V. Guledgud, and K. Patil, "Infraorbital ethmoid (Haller's) cells: a panoramic radiographic study," Dentomaxillofacial Radiology, vol. 41, no. 4, pp. 305-308, 2012.

[19] R. P. Desjardins, “Implants for the edentulous patients," Dental Clinics of North America, vol. 40, no. 1, pp. 195-215, 1996.

[20] N. A. Sandler, V. Ziccardi, and M. Ochs, "Differential diagnosis of jaw pain in the elderly." Journal of the American Dental Association (1939), vol. 126, no. 9, pp. 1263-1272, 1995.

[21] I. J. Santos German, D. V. Buchaim, J. C. Andreo et al., "Identification of the bony canal of the posterior superior alveolar nerve and artery in the maxillary sinus: tomographic, radiographic, and macroscopic analyses," Scientific World Journal, vol. 2015, Article ID 878205, 2015.

[22] P. P. Jaju and S. P. Jaju, "Cone-beam computed tomography: Time to move from ALARA to ALADA," Imaging Science in Dentistry, vol. 45, no. 4, pp. 263-265, 2015.

[23] M. Capelli and P. Gatti, "Radiological study of maxillary sinus using CBCT: Relationship between mucosal thickening and common anatomic variants in chronic rhinosinusitis," Journal of Clinical and Diagnostic Research, vol. 10, no. 11, pp. MC07MC10, 2016.

[24] G. Göçmen, M. O. Borahan, S. Aktop, A. Dumlu, F. N. Pekiner, and K. Göker, "Effect of septal deviation, concha bullosa and haller's cell on maxillary sinus's inferior pneumatization; a retrospective study," The Open Dentistry Journal, vol. 9, pp. 282286, 2015.

[25] R. Mathew, G. Omami, A. Hand, D. Fellows, and A. Lurie, "Cone beam CT analysis of Haller cells: Prevalence and clinical significance," Dentomaxillofacial Radiology, vol. 42, no. 9, Article ID 20130055, 2013.

[26] K. Orhan, M. Misirli, S. Aksoy et al., "Morphometric analysis of the infraorbital foramen, canal and groove using cone beam CT: Considerations for creating artificial organs," The International Journal of Artificial Organs, vol. 39, no. 1, pp. 28-36, 2016.

[27] A. Sinanoglu, K. Orhan, S. Kursun, B. Inceoglu, and B. Oztas, "Evaluation of optic canal and surrounding structures using cone beam computed tomography: Considerations for maxillofacial surgery," The Journal of Craniofacial Surgery, vol. 27, no. 5, pp. 1327-1330, 2016.

[28] S. E. J. Connor, "The Skull Base in the Evaluation of Sinonasal Disease: Role of Computed Tomography and MR Imaging," Neuroimaging Clinics of North America, vol. 25, no. 4, pp. 619651, 2015.

[29] K.-I. Ohshima, Y. Sogabe, and Y. Sato, "The usefulness of infraorbital nerve enlargement on MRI imaging in clinical diagnosis of IgG4-related orbital disease," Japanese Journal of Ophthalmology, vol. 56, no. 4, pp. 380-382, 2012.

[30] S. Amjadi, W. O. Chan, S. Rajak et al., "A case of traumatic infraorbital neuroma," Journal of Oral and Maxillofacial Surgery, vol. 21, no. 4, pp. 471-473, 2017.

[31] L. P. Bosse and T. D. Taylor, "Problems associated with implant rehabilitation of edentulous maxilla," Dental Clinics of North America, vol. 42, no. 1, pp. 117-127, 1998. 


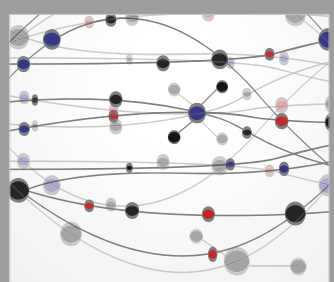

The Scientific World Journal
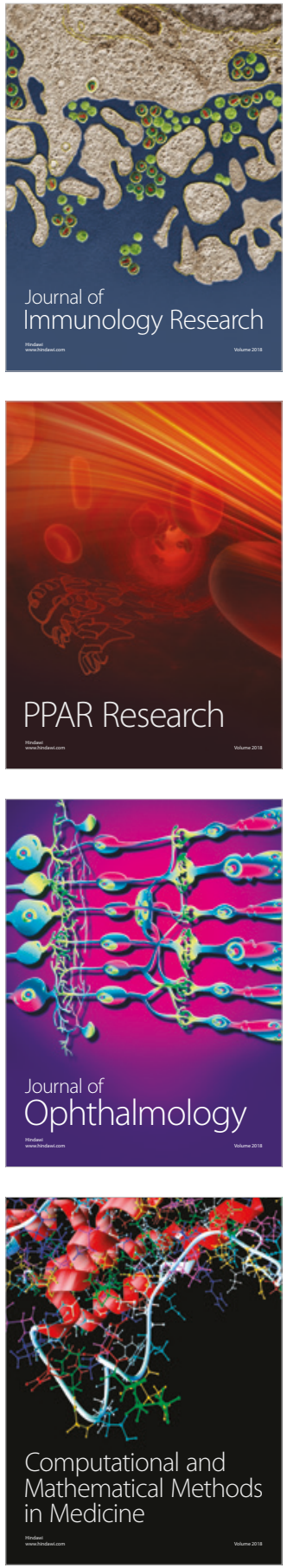

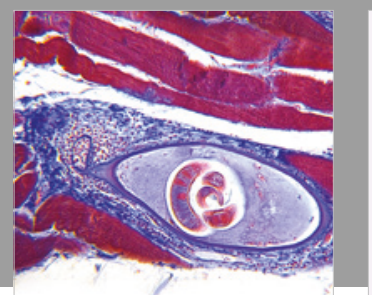

Gastroenterology Research and Practice

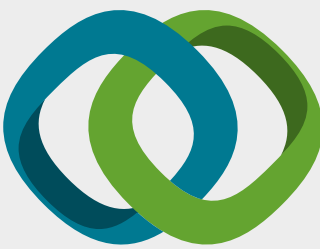

\section{Hindawi}

Submit your manuscripts at

www.hindawi.com
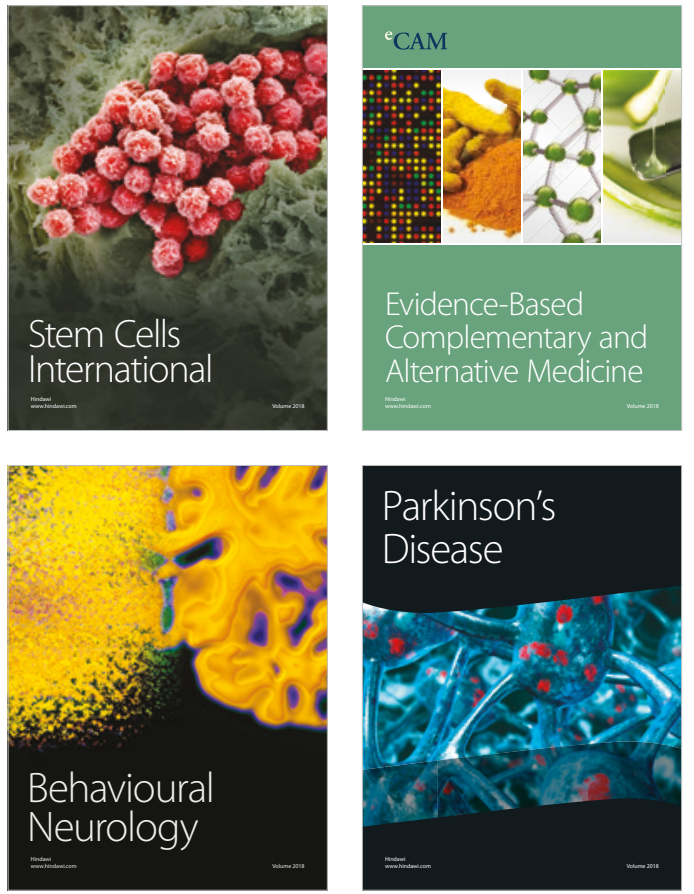

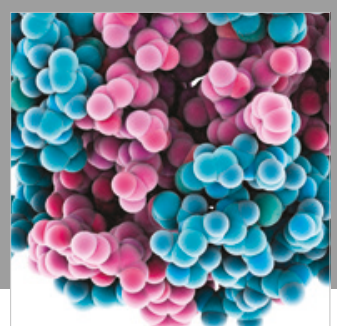

ournal of

Diabetes Research

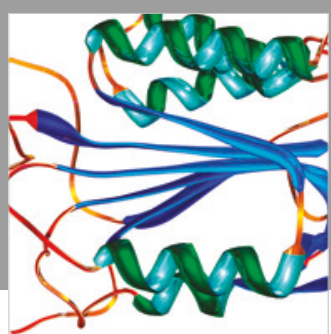

Disease Markers
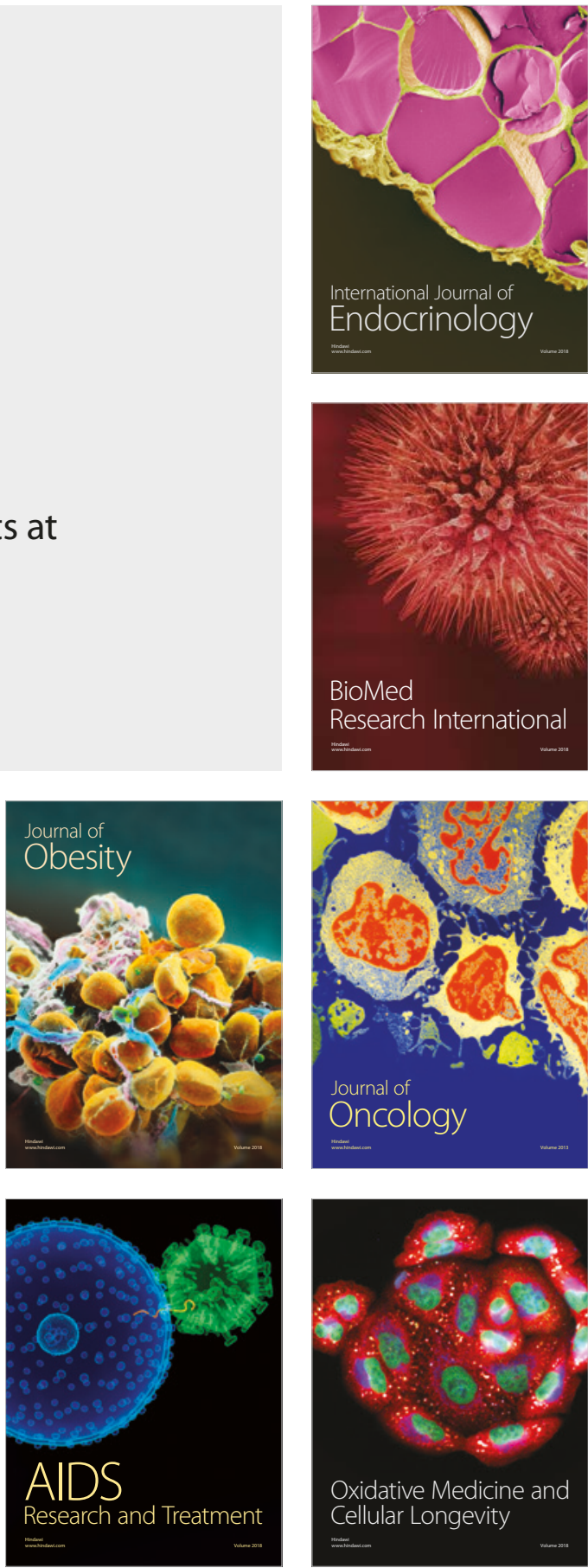